\title{
Comparison of different tests used in mapping the Greek virgin olive oil production for the determination of its total antioxidant capacity
}

\author{
By Katerina S. Minioti ${ }^{a}$ and Constantinos A. Georgiou ${ }^{a, *}$ \\ ${ }^{a}$ Chemistry Laboratory, Agricultural University of Athens, 75 Iera Odos, 11855 \\ Athens, Greece \\ ( ${ }^{\star}$ Corresponding author: cag@ aua.gr)
}

\section{RESUMEN}

Comparación de diferentes test para la determinación de la capacidad antioxidante total en el mapeo de la producción de aceite de oliva virgen Griego

El objetivo de este estudio es el mapeo de la actividad antioxidante total (TAC) de 50 aceites de oliva Griego de los años 2005-2006 de acuerdo a su región y cultivar, y se comparan los ensayos del ácido 2, 2'-azino-bis (3-etilbenzo-tiazolina-6-sulfónico (ABTS), del 2,2-difenil-1-picrlhidrazil radical (DPPH) y de Folin-Ciocalteu. La capacidad antioxidante determinada en la fracción hidrofílica varió entre 5.42-22.5 mM de ácido gálico $\mathrm{Kg}^{-1}$ de aceite para el método ABTS y 1.29$9.95 \mathrm{mM} \mathrm{Kg}^{-1}$ de aceite para el método de DPPH mientras que la TAC del aceite de oliva completo varió entre 77-177 $\mathrm{mM} \mathrm{Kg}{ }^{-1}$ de aceite por el método de DPPH. Los resultados del contenido de fenoles totales varió entre 3.8 y $29.4 \mathrm{mM}$ $\mathrm{Kg}^{-1}$ de aceite. El contenido total de fenoles correlaciona con la capacidad total antioxidante evaluada en la fracción hidrofílica en los ensayos de DPPH $(r=0.89)$ y de ABTS $(r=$ 0.69 ). Los valores de DPPH de la fracción hidrofílica correlacionan significativamente con los valores de ABTS $(r=0.81)$. Sin embargo, los valores de DPPH para el aceite de oliva completo correlacionan pobremente con el ensayo ABTS, el método de Folin-Ciocalteu y el ensayo de DPPH de la fracción hidrofílica. Aunque el contenido de fenoles totales muestra una buena correlación con los valores de ABTS y DPPH y podría servir como un útil indicador de la capacidad antioxidante del aceite de oliva, el uso de una batería de test contribuye a una mejor caracterización de la capacidad antioxidante del aceite de oliva.

PALABRAS CLAVE: ABTS - Aceite de oliva - Antioxidantes fenólicos - Capacidad antioxidante total - DPPH Folin-Ciocalteu

\section{SUMMARY}

Comparison of different tests used in mapping the Greek virgin olive oil production for the determination of its total antioxidant capacity

This study aims to map the total antioxidant capacity (TAC) of 50 Greek olive oil samples from the 2005-2006 season according to production region and cultivar and to compare the 2, 2'-azino-bis (3-ethylbenzo-thiazoline-6sulfonic acid (ABTS), 2, 2-diphenyl-1-picrylhydrazyl radical (DPPH) and Folin-Ciocalteu tests for use with olive oil. Antioxidant capacities determined in the hydrophilic fraction range between 5.42 - $22.5 \mathrm{mM}$ gallic acid $\mathrm{Kg}^{-1}$ olive oil for the ABTS method and $1.29-9.95 \mathrm{mM} \mathrm{Kg}^{-1}$ for the DPPH method while in total, olive oil TAC ranges between $77-177$
$\mathrm{mM} \mathrm{Kg}{ }^{-1}$ as assessed by the DPPH method. The results of total phenol content range between 3.8 and $29.4 \mathrm{mM} \mathrm{Kg}^{-1}$ olive oil. Total phenol content correlates with total antioxidant capacity assessed in the hydrophilic fraction through the DPPH $(r=0.89)$ and the ABTS $(r=0.69)$ assays. The hydrophilic fraction DPPH values correlate significantly with the ABTS values $(r=0.81)$. However, the DPPH values for total olive oil correlate poorly with the ABTS assay, the Folin-Ciocalteu method and the DPPH assay in hydrophilic fraction. Although total phenolic content shows good correlation with ABTS and DPPH values and could serve as a useful indicator for olive oil antioxidant capacity, the use of a battery of tests contributes to better characterization of the antioxidant capacity of olive oil.

KEY-WORDS: ABTS - DPPH - Folin-Ciocalteu - Olive oil - Phenolic antioxidants - Total antioxidant capacity.

\section{INTRODUCTION}

Olive oil, which is the main lipid source in the Mediterranean diet, is obtained from the fruit of several cultivars of the olive tree Olea europea L.. Each cultivar exhibits specific physical and biochemical characteristics, providing oils with different compositions and properties. The composition of olive oil, and its sensorial characteristics, besides being strongly dependent on the cultivar, is also influenced by several other factors like climatic and agronomic conditions, the time of harvest and agricultural practices. Extra virgin olive oil is a rich source of natural antioxidants such as tocopherols, carotenoids, sterols and phenolic compounds. Studies indicate that these phytochemicals, especially polyphenols, have high free-radical scavenging activity, which helps reduce the risk of chronic diseases, such as cardiovascular disease, cancer and age-related neuronal degeneration (Mascitelli et al., 2007). Free radicals are generated in the human body through aerobic respiration and exist in different forms, including superoxide, hydroxyl, hydroperoxyl, peroxyl and alkoxyl radicals. Natural antioxidant enzymes in healthy individuals remove these free radicals while dietary antioxidants assist the body in neutralizing free radicals. Therefore, it is important to consume foods with high contents of antioxidants, such as virgin olive oil, to reduce the harmful effects of oxidative stress. 
Data on the antioxidant content of olive oil is very important for food scientists, doctors, industries and consumers. Although various methodologies have been developed for the quantitative assessment of different antioxidant compounds in olive oil, the use of a single index to characterize the antioxidant potential of olive oil is beneficial (Tuberoso et al., 2007). For this, several analytical methods have been developed for olive oil total antioxidant capacity (TAC) assessment. A number of these methods measure the inhibition of a stable or an artificially generated radical upon olive oil addition. The DPPH radical scavenging assay is the commonly used method for olive oil TAC estimation and is based on the disappearance of the purple color of the radical solution, through scavenging reactions with antioxidants, measured spectrophotometrically at $515 \mathrm{~nm}$. This method has been developed for both the hydrophilic (Espin et al., 2000; Gorinstein et al., 2003; Valavanidis et al., 2004) and lipidic (Espin et al., 2000) fraction. In polar fractions, the ABTS radical scavenging assay has also been used (Mannimo et al., 1999; Pellegrini et al., 2001; Gorinstein et al, 2003; Bendini et al., 2006). The ABTS assay is based on the disappearance of the blue-green color of the radical solution, upon consumption by antioxidants, measured spectrophotometrically at $734 \mathrm{~nm}$. Another index related to olive oil TAC is total phenolic content as measured through the FolinCiocalteu assay (Montedoro et al., 1992; Capannesi et al., 2000). Olive oil total phenolics are determined spectrophotometrically at $765 \mathrm{~nm}$ in methanolic extracts.

This work aims to map the antioxidant capacity of Greek olive oils according to production region and cultivar. Furthermore, the effect of cultivar and region on results is indicated and the ABTS, DPPH and Folin-Ciocalteu assays are compared during the analysis of the 2005-2006 harvest.

\section{MATERIALS AND METHODS}

\subsection{Chemicals}

Gallic acid monohydrate was supplied from Riedel-de Haën. 2, 2-Diphenyl-1-picrylhydrazyl radical (DPPH), of $90 \%$ grade, 2, 2'-Azino-bis (3-ethylbenzothiazoline-6-sulfonic acid) diammonium salt (ABTS), of $98 \%$ grade, and peroxidase (HRP), type II, $222 \mathrm{U}$ $\mathrm{mg}^{-1}$, were obtained from Sigma. Ethyl acetate and methanol of analytical grade were obtained from Merck and n-hexane, of 95\% grade, was from Lab Scan. Hydrogen peroxide, $30 \%$ in water solution, of analytical grade, sodium acetate, of pro analysis grade, and Folin-Ciocalteu reagent were purchased from Merck. Sodium carbonate was obtained from SDS. Distilled water was used throughout.

\subsection{Apparatus}

Experiments for ABTS, DPPH and Folin-Ciocalteu assays were performed with a double beam Jasco
V-550 UV-Vis spectrophotometer. An Orion ${ }^{\circledR}$ pH-meter was used to prepare aqueous acetate and carbonate buffers.

\subsection{Olive oil samples}

Fifty extra virgin olive oil samples originating from Messinia, Zakinthos, Chalkidiki, Iraklio, Chania, Lesbos, Lakonia, Pieria, Arkadia and Euvia, belonging to Koroneiki, Prasinolia, Athinolia, Adramatini, Kolovi, Mavrolia, Kolindrou, Megaron and Chalkidikis cultivars from Greece were stored at $-80^{\circ} \mathrm{C}$ and protected from light until analysis. Samples came from the 2005-2006 harvest. Samples had a fully characterized profile, according to acidity \% oleic acid, peroxide number, Rancimat value, $\mathrm{K}_{232}, \mathrm{~K}_{270}$, total sterols, \% content in erythrodiol-oubaol, cholysterol, brassicasterol, campesterol, b-sitosterol, D-7 stigmasterol, \% content in fatty acids C16:0, C16:1, C17:0, C17:1, C18:0, C18:1, C18:2, C18:3, C20:0, C20:1, C22:0.

\subsection{Hydrophilic extracts}

$0.50 \mathrm{~g}$ of olive oil sample was diluted $1: 1$ (v:v) in $\mathrm{n}$-hexane. Diluted samples were extracted by two $0.50 \mathrm{~mL}$ portions of methanol:water 80:20 (v:v) solvent. After separation from the lipidic fraction by $5 \mathrm{~min}$ of centrifugation at $5000 \mathrm{rpm}$, the two hydrophilic extracts were combined.

\subsection{DPPH assay: total olive oil and hydrophilic fraction}

A $1.3 \times 10^{-4} \mathrm{M}$ working solution of the DPPH radical in ethyl acetate which shows an absorbance of approximately 1.2 at $515 \mathrm{~nm}$ was prepared daily. Olive oil aliquots of $20,80,120$ and $180 \mathrm{mg}$ or 170 $\mu \mathrm{L}$ of olive oil hydrophilic extract were added to 4.0 $\mathrm{mL}$ DPPH working solution. Mixtures were vigorously stirred for a few seconds and kept in the dark for 1 h. Absorbencies were measured at $515 \mathrm{~nm}$ against ethyl acetate. Olive oil antioxidants scavenge the DPPH cation radical, resulting in decolorization of its purple solution. Total antioxidant capacity, expressed as $\mathrm{mmol} \mathrm{L}^{-1}$ of gallic acid equivalents (GAE) per kilogram of oil, is calculated using the appropriate amount that shows $50 \%$ absorbance inhibition as determined by plotting absorbencies against the amount of olive oil .

\subsection{ABTS assay in the hydrophilic fraction}

The ABTS method as described by Pellegrini et al. (2001) was modified by changing the oxidation reagent from potassium persulfate to hydrogen peroxide using HRP catalyst: ABTS, $\mathrm{H}_{2} \mathrm{O}_{2}$ and HRP stock solutions at concentrations of $20,20 \mathrm{mM}$ and $55.5 \mathrm{IU} \mathrm{mL}^{-1}$, respectively, were prepared in 0.020 $\mathrm{M}$ acetate buffer, $\mathrm{pH} 4.6$ and were stable for over a month stored at $0-4{ }^{\circ} \mathrm{C}$. An ABTS radical cation working solution was prepared by mixing $16,0.16$ and $5.4 \mathrm{~mL}$ of the three stock solutions, respectively 
in a $100 \mathrm{~mL}$ volumetric flask. The formation of ABTS radical cation is completed within $3 \mathrm{~h}$ in the dark. A fifty fold excess of ABTS over $\mathrm{H}_{2} \mathrm{O}_{2}$ was chosen in order to prevent possible reactions between the antioxidants and unreacted hydrogen peroxide. It should be noted that the presence of ABTS is necessary to stabilize the ABTS radical cation (Labrinea and Georgiou, 2005). After reaction completion, the volumetric flask is filled up with methanol. The thus prepared working ABTS radical cation solution contains $1.6 \mathrm{mM}$ ABTS and $1.6 \mathrm{mM}$ $\mathrm{ABTS}^{+\bullet}$ and shows an absorbance of approximately 1.2 at $734 \mathrm{~nm}$. 20, 100, 180 and $260 \mu \mathrm{L}$ of hydrophilic extract were added to $4.0 \mathrm{~mL}$ of working solution and brought to $5.0 \mathrm{~mL}$ final volume with methanol:water 80:20 (v:v). Mixtures were vigorously stirred for a few seconds and kept in the dark for $1 \mathrm{~h}$. Absorbencies were measured at $734 \mathrm{~nm}$ against methanol:water 80:20 (v:v). Olive oil antioxidants scavenge the ABTS cation radical, resulting in its decolorization. Total antioxidant capacity, expressed as $\mathrm{mmol} \mathrm{L}^{-1}$ of gallic acid equivalents (GAE) per kilogram of oil, is calculated using the appropriate volume that shows $50 \%$ absorbance inhibition as determined by plotting absorbencies against the hydrophilic extract volumes.

\subsection{Total phenol content}

Total phenol content was measured using the Folin-Ciocalteu method as described by Capannesi et al. (2000). A calibration curve of gallic acid was acquired in the concentration range of 1-50 $\mu \mathrm{M}$.

\section{RESULTS AND DISCUSSION}

\subsection{Determination of antioxidant capacity}

The gallic acid calibration curves used for transforming absorbance inhibition values (AI) to gallic acid equivalents (GAE, $\mu \mathrm{M})$, for $A B T S$ and DPPH assays, are: $\mathrm{Al}_{\mathrm{ABTS}} \times 10^{2}=(6.10 \pm 0.71) \times$ $\mathrm{GAE}+(6.2 \pm 4.0), \mathrm{r}=0.997$ and $\mathrm{Al}_{\mathrm{DPPH}} \times 10^{2}=$ $(6.78 \pm 0.31) \times \mathrm{GAE}+(1.4 \pm 2.6), r=0.998$. The concentration range is $2-50 \mu \mathrm{M}$.

A linear correlation between the absorbance inhibition of the DPPH or ABTS radical solutions and the mass of both hydrophilic extract and olive oil sample was observed for all analyzed olive oil samples. Figure 1 shows this linear correlation, for three olive oil samples with high, middle and low TAC values. A higher slope indicates higher antioxidant activity. The linear dose response relation justifies the use of extrapolation for determining IC50\% concentrations. In this paper all results are per $\mathrm{kg}$ olive oil.

Antioxidant capacities of the analyzed extra virgin olive oil samples measured by ABTS and DPPH assays are shown in Table 1. Olive oil samples are from different cultivars and origins. Antioxidant capacities determined in the hydrophilic fraction range between $5.42-22.5$ and $1.29-9.95$ $\mathrm{mM}$ gallic acid $\mathrm{Kg}^{-1}$ olive oil for ABTS and DPPH methods, respectively. For total olive oil, TAC ranges between 77 and $177 \mathrm{mM}$ gallic acid $\mathrm{Kg}^{-1}$ measured by the DPPH method. Results from the DPPH assay in total olive oil are higher than those in the hydrophilic fraction. This is expected as the DPPH assay in total olive oil also assesses tocopherols which show a synergistic action with phenolics (Espin et al., 2000). The mean TAC values for ABTS and DPPH in the hydrophilic fraction are $13.1 \pm 4.2$ and $5.4 \pm 2.2 \mathrm{mM}$ gallic acid $\mathrm{Kg}^{-1}$, respectively. It is interesting to note that for the hydrophilic fraction, the DPPH test gives systematically lower results than the ABTS assay. This is probably due to the different reaction properties of the olive oil antioxidants extracted in the hydrophilic fraction.

$\%$ RSD values for the DPPH assay in total olive oil were in the range of $2.2 \%$ to $3.5 \%$, while for the

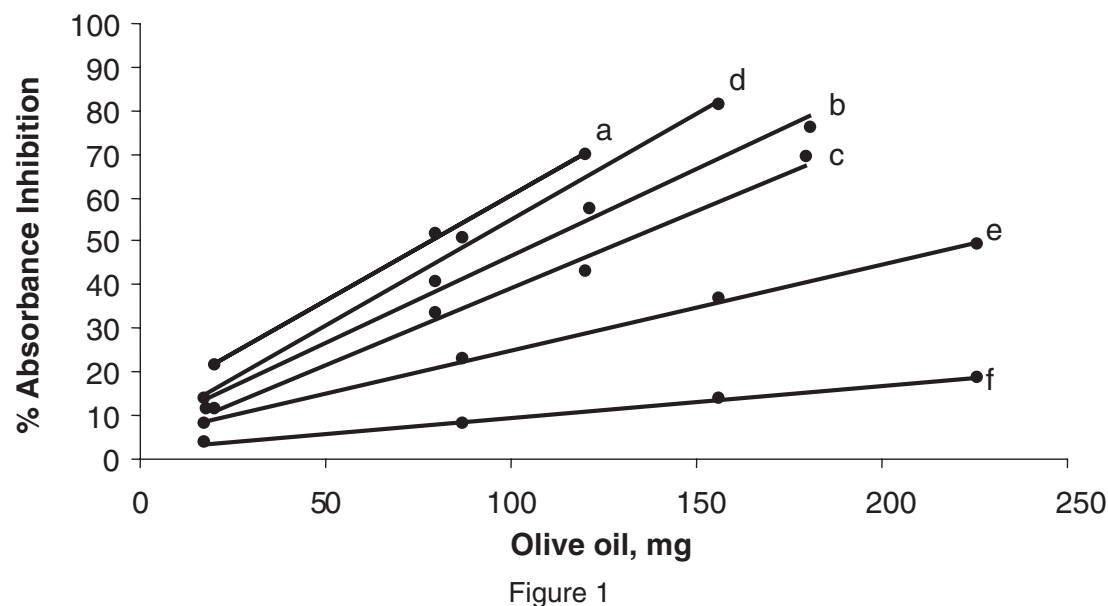

Relationship between the amount of olive oil sample and \% absorbance inhibition as measured through the $\operatorname{DPPH}(a, b, c)$ and ABTS $(d, e, f)$ assays for three olive oil samples with high (a \& d); middle (b \& e); and low (c \& f) TAC values. Slopes \pm SD and correlation coefficients where: (a) $7.73 \pm 0.20,0.9997$; (b) $6.39 \pm 0.44$, 0.995; (c) $5.66 \pm 0.39,0.995$; (d) $7.77 \pm 0.41,0.998$; (e) $3.149 \pm 0.094,0.9991$; (f) $1.159 \pm 0.046,0.998$. 
Table 1

Total Antioxidant Capacity and Total phenolics of different Greek cultivar-origin olive oils determined through DPPH, ABTS and Folin-Ciocalteu assays

\begin{tabular}{|c|c|c|c|c|c|c|}
\hline \multirow[b]{3}{*}{ Sample No } & \multirow[b]{3}{*}{ Origin } & \multirow[b]{3}{*}{ Cultivar } & \multirow{3}{*}{$\begin{array}{c}\text { Phenolics }^{\mathrm{a}} \\
\text { Folin- } \\
\text { Ciocalteu }\end{array}$} & \multirow[b]{2}{*}{ ABTS } & \multirow{2}{*}{$\frac{\text { TAC }^{\mathrm{a}}}{\mathrm{DPPH}}$} & \multirow[b]{2}{*}{ DPPH } \\
\hline & & & & & & \\
\hline & & & & \multicolumn{2}{|c|}{ Hydrophilic fraction } & Total olive oil \\
\hline 1 & Chania & Koroneiki & 12.3 & 8.65 & 3.67 & 90.5 \\
\hline 2 & $-/ /-$ & $-/ /-$ & 14.3 & 8.51 & 4.03 & 95.1 \\
\hline 3 & $-/ /-$ & $-/ /-$ & 24.9 & 14.1 & 7.10 & 122 \\
\hline 4 & $-/ /-$ & $-/ /-$ & 10.3 & 11.8 & 3.95 & 79 \\
\hline 5 & $-/ /-$ & $-/ /-$ & 15.6 & 14.8 & 5.22 & 96 \\
\hline 6 & $-/ /-$ & $-/ /-$ & 16.6 & 19.2 & 7.32 & 101 \\
\hline 7 & $-/ /-$ & $-/ /-$ & 19.2 & 18.4 & 6.24 & 113 \\
\hline 8 & $-/ /-$ & $-/ /-$ & 10.1 & 11.1 & 4.03 & 85 \\
\hline 9 & Messinia & $-/ /-$ & 10.0 & 5.71 & 3.06 & 90.2 \\
\hline 10 & $-/ /-$ & $-/ /-$ & 7.8 & 5.42 & 2.61 & 83.4 \\
\hline 11 & $-/ /-$ & $-/ /-$ & 12.1 & 8.23 & 4.10 & 126 \\
\hline 12 & $-/ /-$ & $-/ /-$ & 17.0 & 8.77 & 5.35 & 98.3 \\
\hline 13 & $-/ /-$ & $-/ /-$ & 10.2 & 6.86 & 2.44 & 96.3 \\
\hline 14 & $-/ /-$ & $-/ /-$ & 14.4 & 16.1 & 5.92 & 117 \\
\hline 15 & $-/ /-$ & $-/ /-$ & 15.3 & 14.7 & 4.86 & 93 \\
\hline 16 & $-/ /-$ & $-/ /-$ & 3.8 & 7.28 & 1.29 & 77 \\
\hline 17 & $-/ /-$ & $-/ /-$ & 15.3 & 16.5 & 4.51 & 96 \\
\hline 18 & $-/ /-$ & Mavrolia & 15.3 & 13.7 & 6.23 & 123 \\
\hline 19 & $-/ /-$ & $-/ /-$ & 11.0 & 14.3 & 5.13 & 125 \\
\hline 20 & Lakonia & Mixed & 11.7 & 13.7 & 5.92 & 111 \\
\hline 21 & $-/ /-$ & Koroneiki & 21.1 & 12.1 & 6.44 & 114 \\
\hline 22 & $-/ /-$ & Athinolia & 9.4 & 6.48 & 2.84 & 125 \\
\hline 23 & $-/ /-$ & $-/ /-$ & 29.4 & 18.6 & 7.51 & 117 \\
\hline 24 & $-/ /-$ & $-/ /-$ & 25.1 & 22.5 & 9.57 & 115 \\
\hline 25 & $-/ /-$ & $-/ /-$ & 9.0 & 11.1 & 2.94 & 77 \\
\hline 26 & $-/ /-$ & $-/ /-$ & 10.8 & 13.7 & 3.13 & 93 \\
\hline 27 & $-/ /-$ & $-/ /-$ & 15.2 & 14.5 & 5.61 & 129 \\
\hline 28 & Zakinthos & Koroneiki & 13.2 & 10.8 & 5.91 & 122 \\
\hline 29 & $-/ /-$ & $-/ /-$ & 24.7 & 17.4 & 9.12 & 119 \\
\hline 30 & $-/ /-$ & $-/ /-$ & 19.6 & 13.2 & 6.95 & 117 \\
\hline 31 & $-/ /-$ & $-/ /-$ & 22.9 & 17.0 & 9.20 & 118 \\
\hline 32 & $-/ /-$ & $-/ /-$ & 8.1 & 10.9 & 3.09 & 96 \\
\hline 33 & $-/ /-$ & $-/ /-$ & 7.6 & 11.4 & 3.25 & 86 \\
\hline 34 & $-/ /-$ & $-/ /-$ & 14.0 & 13.7 & 4.90 & 99 \\
\hline 35 & Euvoia & Megaron & 7.5 & 10.7 & 2.04 & 78 \\
\hline 36 & Pieria & $-/ /-$ & 11.4 & 8.21 & 3.88 & 175 \\
\hline 37 & $-/ /-$ & Kolindrou & 20.3 & 11.7 & 5.79 & 112 \\
\hline 38 & Chalkidiki & Chalkidikis & 26.2 & 22.1 & 9.95 & 110 \\
\hline 39 & $-/ /-$ & $-/ /-$ & 16.0 & 17.1 & 5.58 & 94 \\
\hline 40 & $-/ /-$ & Prasinolia & 21.5 & 8.75 & 5.16 & 127 \\
\hline 41 & $-/ /-$ & $-/ /-$ & 13.8 & 7.01 & 3.28 & 82.6 \\
\hline 42 & Arkadia & Athinolia & 15.9 & 15.8 & 6.30 & 96 \\
\hline 43 & Iraklio & Koroneiki & 24.1 & 15.3 & 8.72 & 131 \\
\hline 44 & $-/ /-$ & $-/ /-$ & 24.2 & 15.5 & 6.26 & 167 \\
\hline 45 & $-/ /-$ & $-/ /-$ & 28.0 & 17.3 & 8.71 & 133 \\
\hline 46 & $-/ /-$ & $-/ /-$ & 21.9 & 17.7 & 8.92 & 148 \\
\hline 47 & $-/ /-$ & $-/ /-$ & 12.0 & 11.9 & 3.21 & 88 \\
\hline 48 & Lesbos & Adramatini & 27.8 & 18.4 & 9.69 & 119 \\
\hline 49 & $-/ /-$ & Kolovi & 17.4 & 11.4 & 4.28 & 177 \\
\hline 50 & $-/ /-$ & $-/ /-$ & 12.3 & 14.3 & 4.36 & 90 \\
\hline
\end{tabular}

${ }^{\mathrm{a}} \mathrm{mM}$ gallic acid equivalents $\mathrm{kg}^{-1}$ olive oil 
hydrophilic fraction, they were between $7 \%$ and $9.9 \%$. For the ABTS method \%RSD values range between $6.9 \%$ and $9.7 \%$. From these results it is clear that precision is lower for the hydrophilic extracts due to the extraction step.

\subsection{Total phenol content}

The total phenol content (TPC) was expressed as $\mathrm{mmol} \mathrm{L}^{-1}$ of gallic acid equivalents (GAE) per kilogram of olive oil, using the equation TPC $x$ $10^{2}=(1.938 \pm 0.066) \times \mathrm{GAE}+(1.8 \pm 1.7), r=$ 0.998 . Results from the analyzed olive oil samples, presented in Table II, range between 3.8 and 29.4 $\mathrm{mM}$ gallic acid $\mathrm{Kg}^{-1}$ olive oil. The mean phenol content is $16 \pm 6.3 \mathrm{mM}$ gallic acid $\mathrm{Kg}^{-1}$. \%RSD values were in the range of $6.4 \%$ to $8.8 \%$. Total phenolic content determined through the Folin method are in a similar range to those determined through the ABTS assay in the hydrophilic fraction.

\subsection{Correlation between total phenol content and the different TAC measurement methods}

It is interesting to examine the relationship between the olive oil total phenol content and the antioxidant capacity measured by different methods. In most cases, the antioxidant capacity assessed in the hydrophilic fraction increases along the phenol content (Table 1). Figure 2 shows the correlation between the TAC values assessed through ABTS assay and the total phenol content, which results in a coefficient of $r=0.69$. The graph slope shows that TAC values measured by the ABTS method are 54\% lower than total phenol content. The correlation between the TAC values assessed through the DPPH assay in hydrophilic fraction and the total phenol content result in a correlation coefficient of $r=0.89$. The graph slope shows that TAC values measured by the DPPH method are $68 \%$ lower than total phenol content. It is clear that the Folin-Ciocalteu method gives higher results. This is in line with previous published data (Gorinstein et al., 2003; Sánchez et al., 2007). This is due to the low specificity of the Folin-Ciocalteu method, as the color reaction can occur with any oxidizable phenolic hydroxy group (Capannesi et al., 2000; Hrncirik et al., 2004). Figure 3 shows the correlation $(r=0.81)$ between DPPH and ABTS methods, both in the hydrophilic fraction. The graph slope shows that TAC values measured by the DPPH method are $57 \%$ lower than those measured by the ABTS method. The correlation between DPPH assay in total olive oil and the ABTS assay is poor $(r=0.22)$ while it is also low with the FolinCiocalteu method $(r=0.50)$ and the DPPH assay in the hydrophilic fraction $(r=0.45)$ (Data not shown).

\subsection{Correlation between TAC, cultivar/origin and olive oil analytical parameters}

The TAC values and the total phenol content of the olive oil samples were compared in groups from the same cultivar, origin or cultivar-origin together. Table 2 shows the correlation coefficients found among results. The critical values at the conventional $5 \%$ testing level along the sampling size are: $0.8783(n=5) ; 0.8114(n=6) ; 0.7545(n$ $=7) ; 0.7067(\mathrm{n}=8) ; 0.6664(\mathrm{n}=9) ; 0.6020(\mathrm{n}=$ $11) ; 0.3610(n=30)$ (Siegel et al., 1996). For the cases that the correlation coefficients are bigger, the correlations are statistically significant, which means that there is indeed an association between the two methods compared. The DPPH assay in hydrophilic extract gave good correlations ( $r$ range between 0.72 and 0.98 ) with the ABTS and the Folin-Ciocalteu method for all origins, cultivars and combinations of cultivar-origin tested. On the other hand, correlations between the DPPH method in olive oil and the other three methods in hydrophilic

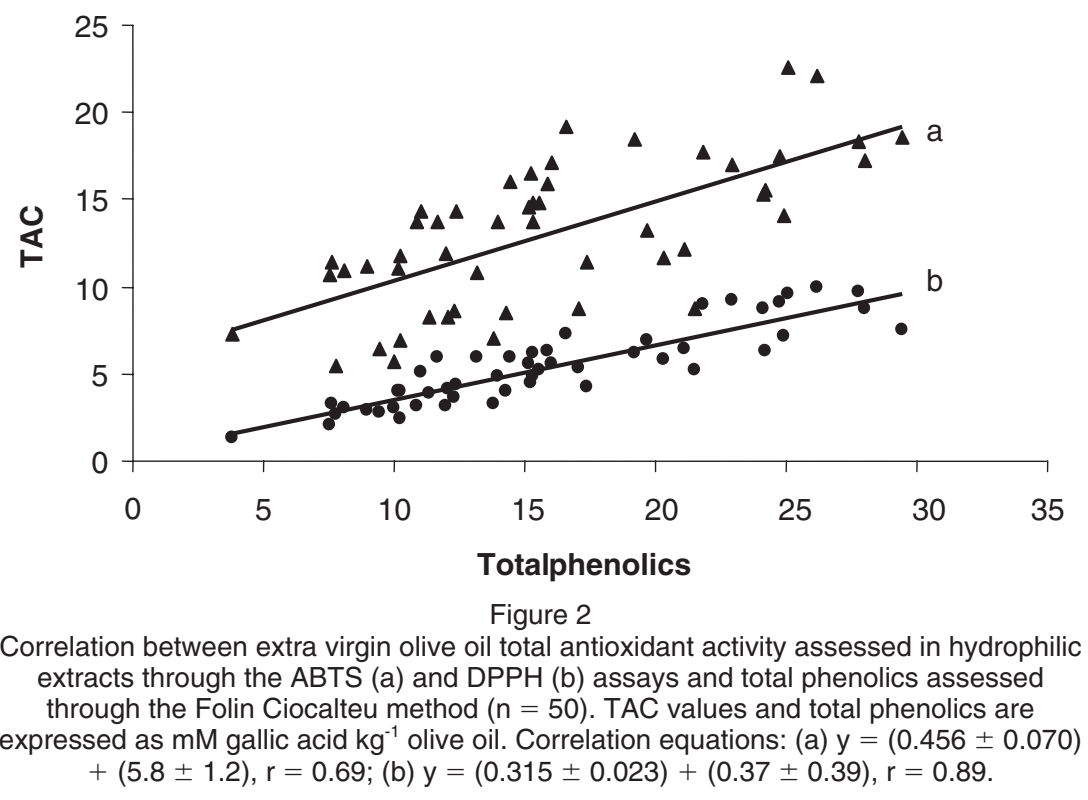




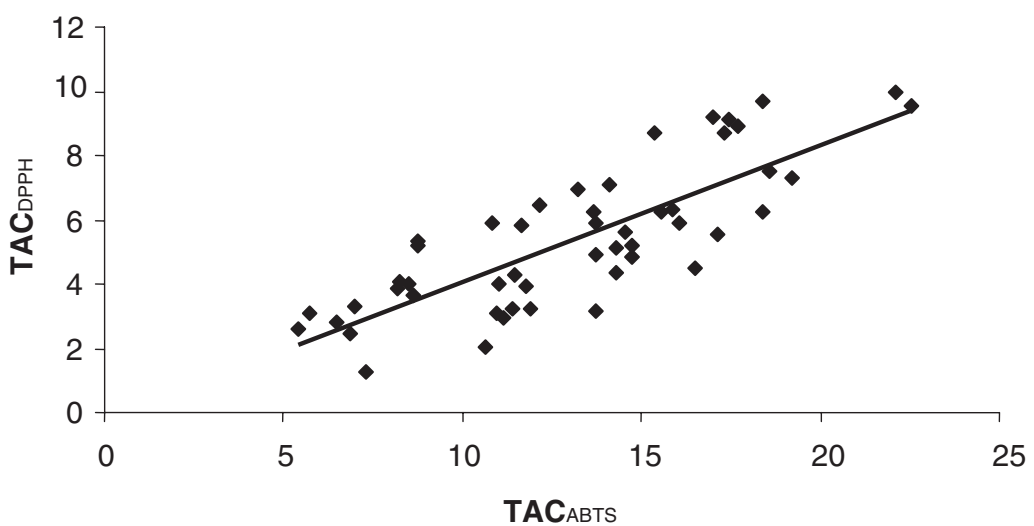

Figure 3

Total antioxidant activity of extra virgin olive oil hydrophilic extracts assessed through DPPH and ABTS assays $(n=50)$. TAC values are expressed in $\mathrm{mM}^{-}$gallic acid $\mathrm{kg}^{-1}$ olive oil. Correlation equation: $\mathrm{y}=(0.428 \pm 0.045)+(-0.22 \pm 0.62), \mathrm{r}=0.81$.

fraction were lower ( $r$ range between 0.10 and 0.98 , smaller than the corresponding critical values in most cases). Among the five origins, Lakonia shows the lowest coefficients ( $r$ range between 0.11 and 0.87 ). The two cultivars tested show significantly different coefficients in the correlation of DPPH in olive oil with the methods in hydrophilic fraction, where Athinolia's is systematically lower. Data was not further treated for the varieties Mavrolia, Megaron, Kolindrou, Chalkidikis, Prassinolia, Kolovi or Adramatini, which we tested using one or two olive oil samples. Although we assessed a small number of Athinolia cultivar samples, data is included as Athinolia and is a dynamic variety in Greece.

The TAC values of the 50 analyzed olive oil samples were also compared with a number of analytical parameters, mentioned in the olive oil samples section, that characterize their profile. No correlation was found between these characteristics and TAC values as determined by the four assays.

\section{CONCLUSIONS}

There were good correlations among the hydrophilic antioxidant activities measured by DPPH and ABTS, suggesting that these methods have a similar predictive capacity of olive oil antioxidant activity. High correlations between Folin-Ciocalteu, $\mathrm{DPPH}$ and ABTS methods indicate that the total phenolic content can be used as an indicator for olive oil antioxidant activity assessed in the hydrophilic

Table 2

Correlation between TAC and total phenol content results in olive oil samples classified according to origin, cultivar and origin-cultivar

\begin{tabular}{|c|c|c|c|c|}
\hline Method & Folin-Ciocalteu & ABTS in extract & DPPH in extract & DPPH in olive oil \\
\hline \multirow[t]{5}{*}{ Folin-Ciocalteu } & & $0.52^{1^{*}}$ & $0.83^{1}$ & $0.98^{1}$ \\
\hline & & $0.63^{2}$ & $0.87^{2}$ & $0.48^{2^{*}}$ \\
\hline & - & $0.77^{3}$ & $0.87^{3}$ & $0.39^{3^{*}}$ \\
\hline & & $0.90^{4}$ & $0.98^{4}$ & $0.78^{4}$ \\
\hline & & $0.83^{5^{*}}$ & $0.84^{5^{*}}$ & $0.74^{5^{*}}$ \\
\hline \multirow[t]{5}{*}{ ABTS in extract } & $0.71^{a}$ & & $0.85^{1}$ & $0.54^{1^{*}}$ \\
\hline & $0.85^{b}$ & & $0.75^{2}$ & $0.48^{2^{*}}$ \\
\hline & $0.67^{2 a}$ & - & $0.86^{3}$ & $0.11^{3^{*}}$ \\
\hline & $0.85^{3 b}$ & & $0.87^{4}$ & $0.48^{4^{*}}$ \\
\hline & & & $0.91^{5}$ & $0.73^{5^{*}}$ \\
\hline \multirow{5}{*}{ DPPH in extract } & $0.92^{a}$ & $0.79^{a}$ & & $0.81^{1}$ \\
\hline & $0.90^{b}$ & $0.92^{b}$ & & $0.73^{2}$ \\
\hline & $0.93^{2 a}$ & $0.72^{2 a}$ & - & $0.43^{3^{*}}$ \\
\hline & $0.92^{3 b}$ & $0.92^{3 b}$ & & $0.83^{4}$ \\
\hline & & & & $0.59^{5^{*}}$ \\
\hline \multirow[t]{4}{*}{ DPPH in olive oil } & $0.78^{a}$ & $0.52^{a}$ & $0.73^{a}$ & \\
\hline & $0.39^{b^{*}}$ & $0.10^{\mathrm{b}^{*}}$ & $0.37^{b^{*}}$ & - \\
\hline & $0.53^{2 a^{*}}$ & $0.35^{2 a^{*}}$ & $0.64^{2 a^{*}}$ & \\
\hline & $0.39^{3 b^{*}}$ & $0.13^{3 b^{*}}$ & $0.42^{3 b^{*}}$ & \\
\hline
\end{tabular}

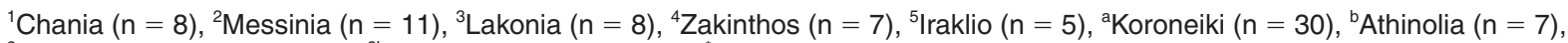

${ }^{2 a}$ Messinia-Koroneiki $(n=9),{ }^{3 b}$ Lakonia-Athinolia $(n=6)$. "The computed correlation is not statistically significant and the null hypothesis that there is no correlation between methods should not be rejected. 
fraction. The DPPH values of lipophilic olive oil fraction correlate poorly with the other methods.

Although the ABTS and DPPH assays gave good correlations with the Folin-Ciocalteu method, the TAC values are systematically lower. In this respect we propose that the use of this battery of tests contributes to better characterization of olive oil antioxidant capacity.

\section{ACKNOWLEDGMENTS}

This work was financially supported by Greek General Secretariat for Research and Technology and Minerva S.A. (Athens, Greece) through a PENED 2003 grant.

\section{REFERENCES}

Bendini A, Cerretani L, Vecchi S, Carrasco-Pancorbo A, Lercker G. 2006. Protective effects of extra virgin olive oil phenolics on oxidative stability in the presence or absence of copper ions. J. Agric. Food Chem. 54, 4880-4887.

Capannesi C, Palchetti I, Mascini M, Parenti A. 2000. Electrochemical sensor and biosensor for polyphenols detection in olive oils. Food Chem. 71, 553-562.

Espin JC, Soler-Rivas C, Wichers HJ. 2000. Characterization of the total free radical scavenger capacity of vegetable oils and oil fractions using 2,2-diphellyl-1-picrylhydrazyl radical. J. Agric. Food Chem. 48, 648-656.

Gorinstein S, Martin-Belloso O, Katrich E, Lojek A, Ciz M, Gligelmo-Miguel N, Haruenkit R, Park YS, Jung ST, Trakhtenberg S. 2003. Comparison of the contents of the main biochemical compounds and the antioxidant activity of some Spanish olive oils as determind by four different radical scavenging tests. J. Nutr. Biochem. 14, 154-159.

Hrncirik K, Fritsche S. 2004. Comparability and reliability of different techniques for the determination of phenolic compounds in virgin olive oil. Eur. J. Lipid Sci. Technol. 106, 540-549.

Labrinea EP, Georgiou CA. 2005. Rapid, fully automated flow injection antioxidant capacity. J. Agric. Food Chem. 53, 4341-4346.

Mannimo S, Buratti S, Cosio MS, Pellegrini N. 1999. Evaluation of the 'antioxidant power' of olive oils based on a FIA system with amperometric detection. Analyst 124, 1115-1118.

Mascitelli L, Pezzetta F, Sullivan JL. 2007. The effect of polyphenols in olive oil on heart disease risk factors. Ann. Intern. Med. 146, 394-394.

Montedoro G, Servili M, Baldioni M, Miniati E. 1992. Simple and hydrolysable phenolic compounds in virgin olive oil. 1. Their extraction, separation, and quantitative and semiquantitative evaluation by HPLC. J. Agric. Food Chem. 40, 1571-1576.

Pellegrini N, Visioli F, Buratti S, Brighenti F. 2001. Direct analysis of total antioxidant activity of olive oil and studies on the influence of heating. J. Agric. Food Chem. 49, 2532-2538.

Sánchez CS, González AMT, García-Parrilla MC, Granados JJQ, de la Serrana HLG, Martínez MCL. 2007. Different radical scavenging tests in virgin olive oil and their relation to the total phenol content. Anal. Chim. Acta 593, 103-107.

Siegel AF, Morgan CJ. 1996. Bivariate data and regression. Statistics and data analysis: an introduction, 2nd ed, John Willey and Sons, Inc., U.S.A., pp. 541-543.

Tuberoso CIG, Kowalczyk A, Sarritzu E, Cabras P. 2007. Determination of antioxidant compounds and antioxidant activity in commercial oilseeds for food use. Food Chem. 103, 1494-1501.

Valavanidis A, Nisiotou C, Papageorgiou Y, Kremli I, Satravelas N, Zinieris N, Zygalaki H. 2004. Comparison of the radical scavenging potential of polar and lipidic fractions of olive oil and other vegetable oils under normal conditions and after thermal treatment. J. Agric. Food Chem. 52, 2358-2365. 